\title{
Efeito do transporte no desenvolvimento de embriões bovinos cultivados in vitro a fresco ou reaquecidos após vitrificação
}

\section{Alessandra de Almeida Ramos ${ }^{1}$, Juliana Polisseni ${ }^{2}$, Wanderlei Ferreira de Sá ${ }^{2}$, Ademir de Moraes Ferreira ${ }^{2}$, Luis Sérgio de Almeida Camargo ${ }^{2}$, Danielle da Silva Folhadella ${ }^{3}$, Luiz Altamiro Garcia Nogueira ${ }^{3}$}

\footnotetext{
${ }^{1}$ Empresa de Pesquisa Agropecuária de Minas Gerais - MG, Brasil.

2 Embrapa Gado de Leite - Juiz de Fora - MG, Brasil.

${ }^{3}$ Universidade Federal Fluminense - RJ, Brasil.
}

RESUMO - Avaliou-se a viabilidade de embriões bovinos cultivados in vitro, a fresco ou reaquecidos após vitrificação, depois detransportados por 6 ou 12 horas. Oócitos obtidos de folículos de ovários coletados em matadouro foram maturados, fecundados e cultivados in vitro. Após sete dias de cultivo, blastocistos com grau de qualidade I e II (segundo o manual da IETS-1998) foram selecionados, envasados em OPS (open pulled straws) e vitrificados em nitrogênio líquido. O reaquecimento foi realizado a $39^{\circ} \mathrm{C}$ pela passagem em soluções de $\mathrm{HM}$ com concentrações decrescentes de sacarose $(0,25 \mathrm{M}$ - $0,15 \mathrm{M}$ ) por cinco minutos em cada solução. Foram avaliados três tratamentos - V0: embriões vitrificados, reaquecidos e cultivados in vitro $(\mathrm{n}=25)$; V6: embriões vitrificados, transportados por 6 horas (simulação em palhetas), reaquecidos e cultivados in vitro $(\mathrm{n}=29)$; e V12: embriões vitrificados, transportados por 12 horas, reaquecidos e cultivados in vitro comparados, cada um, a um tratamento controle, com embriões a fresco- $\mathrm{C} 0$ : embriões a fresco cultivados in vitro $(\mathrm{n}=26)$; C6: embriões a fresco cultivados in vitro após 6 horas de transporte $(\mathrm{n}=30)$; e $\mathrm{C} 12$ : embriões a fresco cultivados in vitro após 12 horas de transporte $(n=30)$. Os embriões foram co-cultivados com células da granulosa em microgotas de TCM 199 acrescido de SFB. Foram avaliadas as taxas de re-expansão e eclosão após 48 horas de cultivo. A análise foi realizada pelo teste do qui-quadrado. As taxas de re-expansão entre os grupos V0, V6 e V12 não diferiram, assim como as taxas de eclosão entre os embriões vitrificados e os controles. As taxas de eclosão, no entanto, diferiram entre os embriões submetidos à vitrificação e os controles. Embriões bovinos produzidos in vitro podem ser transportados a fresco ou vitrificados por períodos de até 12 horas, pois possibilitam taxas de eclosão satisfatórias.

Palavras-chave: criopreservação, DMSO, produção in vitro de embriões

\section{Effect of transportation on development of fresh or vitrified-warmed bovine embryos}

\begin{abstract}
The aim of this study was to evaluate the viability of in vitro produced bovine embryos, fresh or warmed, after submitted to different periods of transportation ( $6 \mathrm{~h}-12 \mathrm{~h}$ ). Oocytes obtained from ovaries collected from slaughterhouse were matured, fertilized and cultured in vitro. After seven days, grades I and II blastocysts (according to IETS manual) were selected and vitrified after exposition to PBS solution with 5\% fetal calf serum (HM), added with 10\% ethylene glycol (EG) and $10 \%$ of dymetil sulfoxide (DMSO), for one minute, followed by HM solution with $20 \%$ EG and $20 \%$ DMSO, for 20 seconds. Embryos were loaded into open pulled straws (OPS) and plunged into liquid nitrogen. Warming was performed at $39^{\circ} \mathrm{C}$ by embryo exposure to decreasing concentration of sucrose $(0.25$ and $0.15 \mathrm{M})$, for five minutes in each step. The warmed embryos were distributed in three groups: V0: in vitro cultured after warmed; V6: embryos loaded into straws and kept for 6 hours at $35^{\circ} \mathrm{C}$, before in vitroculture; and V12: embryos loaded into straws and kept for 12 hours at $35^{\circ} \mathrm{C}$, before in vitro culture. Each group was evaluated by control groups of fresh embryos ( $\mathrm{C} 0, \mathrm{C} 6$ and $\mathrm{C} 12$, respectively). The embryos were co-cultured withcumulus cells in TCM-199 micro droplets added with SFB. Re-expansion and hatching rates after 48 hours in culture were evaluated and results were compared by the Chi-square test. Re-expanded rates among groups V0, V6 and V12 as well as hatching rates among vitrified groups and among control groups did not differ. However, hatching rates were different between vitrified groups and their respective controls. The satisfactory rates of hatching suggest that it is possible to transport warmed and fresh in vitro produced embryos for periods up to 12 hours.
\end{abstract}

Key Words: cryopreservation, DMSO, in vitro production embryo 


\section{Introdução}

A criopreservação de embriões permite o aproveitamento de receptoras com estro natural, reduzindo os custos com a sincronização de estros, além de permitir o transporte de embriões congelados e a programação de nascimentos adequada ao manejo de cada fazenda. Oferece, ainda, condições de armazenamento dos embriões durante o período de teste de progênie e viabiliza a criação de bancos de embriões originados de animais geneticamente superiores, tanto puros como mestiços F1.

É necessário que o método seja adequado e que os embriões apresentem características de tolerância às crioinjúrias. O congelamento lento controlado tem sido a técnica mais amplamente utilizada na criopreservação de embriões produzidos in vivo e in vitro. Entretanto, os embriões produzidos in vitro (PIV) são mais sensíveis à criopreservação e resultam em taxas de gestação menores que as obtidas com embriões produzidos in vivo (Sommerfeld \& Niemann, 1999; Pugh et al., 2000; Diez et al., 2001).

O aumento da sensibilidade dos embriões PIV aos processos de congelamento é parcialmente explicado por mudanças na estrutura embrionária, como menor número de células no embrioblasto, maior número de gotas de lipídeos intracelulares e aumento da permeabilidade da zona pelúcida (Abe et al., 1999; Lazar et al., 2000; Diez et al., 2001). A maior quantidade de lipídeos aumenta a sensibilidade dos embriões a mudanças de temperatura (Rizos et al., 2001; Massip, 2001). Além disso, o número de junções gap nos embriões PIV diminui, reduzindo o grau de compactação do embrioblasto e elevando a susceptibilidade dos embriões às crioinjúrias (Boni et al., 1999; Rizos et al., 2001; Massip, 2001).

Diversos autores concordam que o método de cultivo tem grade importância sobre a menor criotolerância observada nos embriões PIV e que a melhoria nas condições de cultivo pode levar ao aumento nas taxas de sobrevivência embrionária (Vajta et al., 1996). Outra possibilidade para resolver esse problema é encontrar um método de criopreservação apropriado para esses embriões (Martinez et al., 2002).

O método de vitrificação tem se mostrado apropriado para a criopreservação de embriões PIV (Martinez et al., 2002), proporcionando taxas de sobrevivência dos embriões PIV após a vitrificação significativamente maiores que as obtidas após o congelamento lento (Vajta et al., 1996). Taxas de gestação aceitáveis têm sido obtidas após a transferência de embriões PIV vitrificados (Vajta et al., 1996; Donnay et al., 1998; Lazar, 2000; Massip, 2001). Martínezet al.(2002) afirmaram que a vitrificação pode ser utilizada com sucesso na criopreservação de embriões bovinos produzidos in vitro e que essa técnica pode ser utilizada, inclusive, em programas comerciais. A vitrificação é um processo de congelamento que pode ser realizado em contêiner de nitrogênio líquido e que requer pouco tempo para o resfriamento. Com a aplicação dessa técnica, a necessidade de equipamento é menor, pois é possível obter considerável economia no custo do embrião transferido.

Na prática, a utilização da técnica de vitrificação requer o manuseio dos embriões por pessoas especializadas e sob condições que normalmente não existem a campo, principalmente quanto ao reaquecimento dos embriões. Uma possibilidade de superar essa limitação seria reaquecer os embriões em laboratórios e, posteriormente, transportá-los para as fazendas. Neste trabalho, avaliou-se a viabilidade de embriões bovinos produzidos in vitro, vitrificados e posteriormente reaquecidos e submetidos a diferentes períodos de transporte.

\section{Material e Métodos}

O experimento foi realizado na Embrapa Gado de Leite, em Juiz de Fora - MG, durante os meses de julho a setembro de 2004. Os ovários foram obtidos de vacas mestiças abatidas em matadouro e transportados ao laboratório em garrafas térmicas contendo solução fisiológica $(0,9 \% \mathrm{NaCl}$ e $0,1 \mathrm{~g} / \mathrm{L}$ de sulfato de estreptomicina), a temperaturas de 30 a $34^{\circ} \mathrm{C}$. No laboratório, os ovários foram lavados em solução salina e mantidos em banho-maria a $37^{\circ} \mathrm{C}$ até a aspiração. Os folículos com diâmetro entre 2-8 $\mathrm{mm}$ foram aspirados com o auxilio de uma agulha calibre $21 \mathrm{G}$ acoplada a uma seringa de $10 \mathrm{~mL}$. O período entre o abate e o início da aspiração não foi superior a 4 horas. Os oócitos recuperados foram mantidos em meio TALP-HEPES para posterior seleção em microcópio esterioscópico com aumento final de 50x.

Como critérios de avaliação dos oócitos, foram considerados a presença, o número de camadas e o grau de expansão das células do cumulus e o aspecto do citoplasma quanto à cor, homogeneidade e integridade. Foram selecionados os complexoscumulus-oócitos com, no mínimo, três camadas de células do cumulus compactas e o citoplasma homogêneo.

Após seleção, os complexos cumulus-oócitos foram maturados in vitro em placas de quatro poços contendo $400 \mathrm{~mL}$ de meio TCM199 acrescidos de $10 \%$ de soro da vaca em estro e $20 \mathrm{mg} / \mathrm{mL}$ de $\mathrm{FSH}$ em cada poço, conforme descrito por Costa (1994). A maturação foi realizada em estufa incubadora a $38,5^{\circ} \mathrm{C}$, com $5 \%$ de $\mathrm{CO}_{2}$ em ar atmosférico e $95 \%$ de umidade, por 24 horas. 
Depois de maturados, os oócitos foram fertilizados in vitro com sêmen congelado de um touro da raça Holandesa previamente selecionado. Os espermatozóides foram preparados segundo o método de swim up (Parrish et al., 1986) e a fecundação foi realizada em gotas, sob óleo mineral, de $100 \mu \mathrm{L}$ de meio FERT-TALP acrescido de $10 \mu \mathrm{L} / \mathrm{mL}$ de heparina e com $2,0 \times 10^{6}$ espermatozóides $/ \mathrm{mL}$ por um período aproximado de 22 horas nas mesmas condições de maturação.

Os possíveis zigotos foram semidesnudados em meio TALP-HEPES e, em seguida, transferidos para o meio $\mathrm{CR}_{2 \mathrm{aa}}$ acrescido de $10 \%$ de soro fetal bovino em gotas de $50 \mu \mathrm{L}$ de óleo mineral, onde foram co-cultivados com células da granulosa nas mesmas condições de fecundação. Após 48 horas do início do cultivo, $50 \%$ do meio de cultivo foi renovado e a taxa de clivagem avaliada. A taxa de produção de blastocisto e a qualidade dos embriões foram avaliadas no sétimo dia e, quando os embriões se apresentavam em estádio de blastocisto ou blastocisto expandido e grau de qualidade 1 ou 2, segundo o manual da IETS (1998), foram vitrificados.

Os embriões foram vitrificados pela passagem em uma solução de vitrificação constituída de PBS com 5\% de soro fetal bovino (HM) acrescida de $10 \%$ de DMSO e $10 \%$ de etilenoglicol (SV1) por um minuto. Em seguida, foram passados em outra solução de vitrificação (SV2), que consistia de HM acrescido de $20 \%$ de DMSO e $20 \%$ de etilenoglicol por, no máximo, 20 segundos. Os embriões foram, então, envasados em OPS (Open Pulled Straw) e imediatamente imersos em nitrogênio líquido.

Os embriões vitrificados foram reaquecidos pela passagem em soluções de $\mathrm{HM}$ a $38^{\circ} \mathrm{C}$ com duas concentrações diferentes de sacarose $(0,25$ e $0,15 \mathrm{M})$, por cinco minutos em cada uma, sendo então colocados em solução $\mathrm{HM}$ a $38^{\circ} \mathrm{Ce}$, posteriormente, distribuídos em três tratamentos: V0: embriões vitrificados, reaquecidos e cultivados in vitro $(\mathrm{n}=25)$; V6: embriões vitrificados, transportados por 6 horas ( simulação em palhetas), reaquecidos e cultivados in vitro $(\mathrm{n}=29)$; e V12: embriões vitrificados, transportados por 12 horas, reaquecidos e cultivados in vitro. Cada tratamento foi comparado a um tratamento controle, com embriões a fresco: $\mathrm{C} 0$ : embriões a fresco cultivadosin vitro $(\mathrm{n}=26)$; C6: embriões a fresco cultivados in vitro após 6 horas de transporte $(n=30)$; e C12: embriões a fresco cultivados in vitro após 12 horas de transporte $(\mathrm{n}=30)$.

Para simulação do transporte, os embriões foram mantidos em palhetas de $0,25 \mathrm{~mL}$ em placa aquecedora a $33-35^{\circ} \mathrm{C}$, sendo realizadas cinco repetições para cada tratamento.

O cultivo foi realizado em gotas de $50 \mu \mathrm{L}$ de meio TCM-199 tamponado com HEPES e acrescido de 10\% de soro fetal bovino (SFB), na presença de monocamadas de células da granulosa por 48 horas. As taxas de re-expansão, eclosão e degeneração foram avaliadas a cada 24 horas após o início do cultivo.

Os dados (taxas de re-expansão, eclosão e degeneração) foram avaliados pelo teste do qui-quadrado.

\section{Resultados e Discussão}

As taxas de eclosão dos embriões a fresco, assim como as taxas de degeneração, não diferiram $(\mathrm{P}>0,05)$ entre os diferentes períodos de transporte (Tabela 1).

Os resultados deste experimento corroboram os obtidos por outros autores, que também não observaram alterações na viabilidade embrionária após transportarem embriões produzidos in vivo e in vitro por períodos de 6 a 24 horas em diferentes meios de cultivo (Hasler et al., 1997; Leibo \& Winninger, 1986; Mezzalira et al., 2004).

Relatos na literatura confirmam que 20 a $30 \%$ dos embriões produzidos in vitro (PIV) degeneram após serem transportados (Leibo et al., 1986a; Kuwayama et al., 1991; Takahashi et al., 1996). Entretanto, as taxas de degeneração observadas neste experimento foram inferiores a $4 \%$.

As taxas de gestação obtidas com embriões PIV parecem ser inversamente relacionadas ao período de transporte (Yang et al., 1991), mas, neste experimento, não foi possível a avaliação desse parâmetro. Entretanto, as taxas de eclosão e degeneração observadas neste experimento permitem concluir que a viabilidade dos embriões não foi afetada pelo transporte.

O transporte por diferentes períodos também não afetou $(\mathrm{P}>0,05)$ as taxas de re-expansão, eclosão e degeneração dos embriões PIV vitrificados e reaquecidos (Tabela 2). Similarmente, Mezzalira et al. (2004) não observaram diferença entre as taxas de gestação de embriões PIV vitrificados, reaquecidos e transportados por 6 horas e aqueles transferidos logo após o reaquecimento. As taxas de degeneração

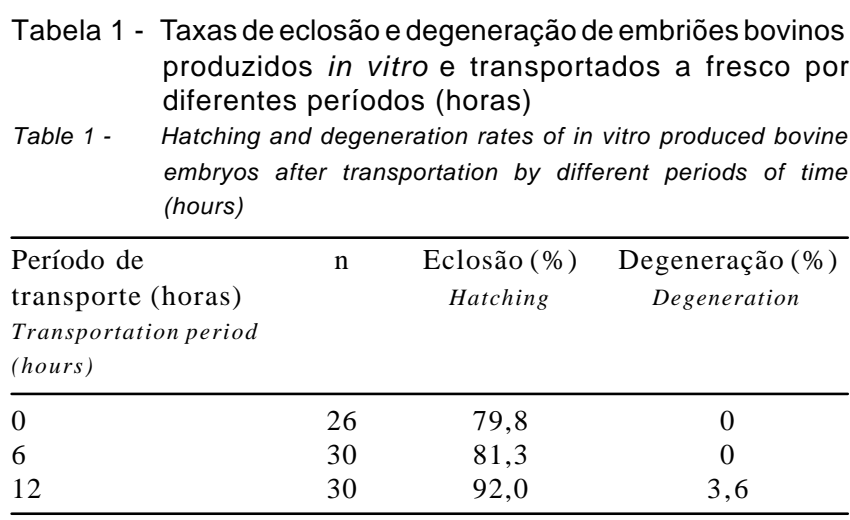

Tabela 1 - Taxas de eclosão e degeneração de embriões bovinos produzidos in vitro e transportados a fresco por embryos after transportation by different periods of time (hours) 
Tabela 2 - Taxas de re-expansão, eclosão e degeneração de embriões bovinos produzidos in vitro e transportados após vitrificação e reaquecimento por diferentes períodos (horas)

Table 2 - Re-expansion, hatching and degeneration rates of in vitro produced bovine embryos, transported after vitrification and warming, by different periods of time (hours)

\begin{tabular}{lcccc}
\hline $\begin{array}{l}\text { Período de transporte (horas) } \\
\text { Transportation period (hours) }\end{array}$ & $\mathrm{N}$ & $\begin{array}{c}\text { Re-expansão(\%) } \\
\text { Re-expansion }\end{array}$ & $\begin{array}{c}\text { Eclosão (\%) } \\
\text { Hatching }\end{array}$ & $\begin{array}{c}\text { Degeneração(\%) } \\
\text { Degeneration }\end{array}$ \\
\hline Oh & 25 & 73,3 & $36,1^{\mathrm{a}}$ & $10,6^{\mathrm{a}}$ \\
$6 \mathrm{~h}$ & 29 & 47,6 & $24,0^{\mathrm{a}}$ & $24,6^{\mathrm{a}}$ \\
$12 \mathrm{~h}$ & 29 & 63,3 & $28,7^{\mathrm{a}}$ & $29,2^{\mathrm{a}}$ \\
\hline
\end{tabular}

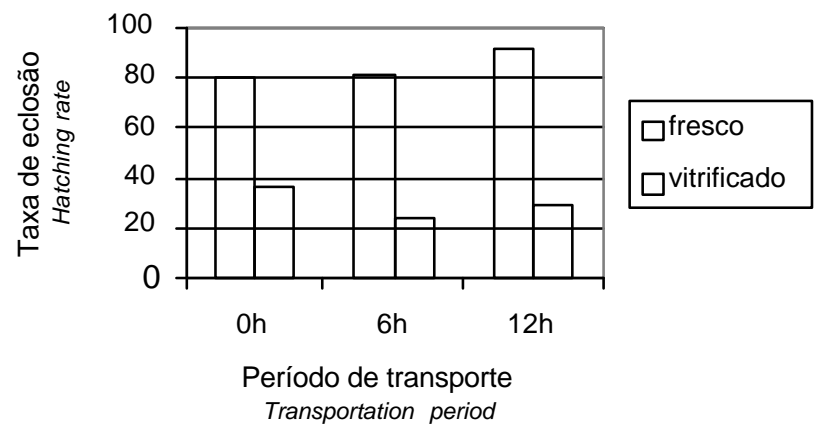

Figura 1 - Taxas de eclosão de embriões bovinos produzidos in vitroe transportados, a fresco ou após vitrificação e reaquecimento, por diferentes períodos.

Figure 1 - Hatching rate of in vitro produced bovine embryos, fresh or warmed, after transportation by different periods of time.

observadas neste trabalho para embriões PIV vitirificados e reaquecidos após 6 e 12 horas de transporte foram semelhantes às relatadas na literatura para embriões PIV transportados a fresco (Leibo et al., 1986b; Kuwayama et al., 1991; Takahashi et al., 1996). Entretanto, são poucos os dados disponíveis na literatura sobre o transporte de embriões submetidos aos processos de vitrificação e reaquecimento. Um fator limitante para difusão da técnica de vitrificação é a ausência de laboratórios adequados nas fazendas para realização do reaquecimento. Uma solução seria o reaquecimento dos embriões em laboratório adequado antes do transporte para as fazendas, todavia, são necessárias mais pesquisas sobre o assunto.

As taxas de eclosão dos embriões vitrificados diferiram $(\mathrm{P}<0,01)$ das obtidas nos seus respectivos tratamentos controles, a fresco (Figura 1), o que confirma os achados de outros autores (Lazar et al., 2000; Camargo et al., 2004), que também observaram diminuição nas taxas de eclosão após a vitrificação. Esse resultado pode ter sido ocasionado pela alta concentração de crioprotetores utilizada nos procedimentos de vitrificação. Segundo Kaidi et al. (1999), concentrações hiperosmóticas de crioprotetores durante o equilíbrio podem promover alterações no volume celular ocasionando danos na membrana celular e, conseqüentemente, afetando a sobrevivência dos embriões. Neste experimento, a intensa desidratação sofrida pelos embriões vitrificados foi evidenciada pela perda parcial ou total da blastocele. Após o reaquecimento, praticamente todos os embriões apresentaram-se semelhantes a mórulas, como consequiência do colabamento da blastocele. Observou-se também redução na qualidade, principalmente em virtude do aumento do número de células de extrusão.

Embora as taxas de re-expansão tenham sido semelhantes às descritas por outros autores (Lazar et al., 2000; Camargo et al., 2004), as taxas de eclosão observadas neste trabalho foram inferiores às relatadas na literatura (Lazar et al., 2000; Martínez et al., 2002; Camargo et al., 2004). A utilização de diferentes sistemas de cultivo in vitro e as diferenças na qualidade dos oócitos podem ser responsáveis pela obtenção de resultados divergentes. A composição de alguns meios de cultivo pode influenciar os desenvolvimentos embrionário, fetal e placentário (Young et al., 1998; Mcevoy, 2003), por afetar a transcrição de determinados genes (Niemann \& Wrenzycki, 2000) e promover alterações morfológicas nos embriões PIV (Cho, 2002; Rizos et al., 2003). Shamsuddin et al. (1994) observaram que embriões cultivados in vitro em presença de soro fetal bovino (SFB), suplemento utilizado neste experimento, apresentaram menor viabilidade e termotolerância. Entretanto, Folhadella et al. (2004), utilizando um sistema de cultivo semelhante, obtiveram taxas de eclosão maiores e não evidenciaram diferenças entre as taxas de eclosão dos embriões cultivados a fresco e daqueles submetidos a vitrificação. Esta diferença também pode ter sido causada pela composição do soro, que é altamente variável dependendo da fonte (animal e/ou fornecedor) e do número de lote (Gomez \& Diez, 2000). Alguns lotes podem ser inertes, tóxicos ou possuir algum tipo de patógeno (Palma, 2001). O co-cultivo com células da granulosa, utilizado em ambos os trabalhos, também é uma fonte de variação para cultivo embrionário.

As taxas de sobrevivência dos embriões PIV verificadas após a vitrificação têm sido significativamente superiores às obtidas após o congelamento lento (Vajta et al., 1996) e um dos fatores que possibilitaria a difusão dessa técnica 
seria realização do reaquecimento no laboratório antes de transportar os embriões para as fazendas, técnica que se mostrou viável nesta pesquisa.

\section{Conclusões}

Embriões cultivados in vitro, a fresco ou reaquecidos após vitrificação, podem ser transportados por períodos de até 12 horas, pois possibilitam taxas de eclosão satisfatórias.

\section{Literatura Citada}

ABE, H.; OTOI, T.; TACHIKAW, S. et al. Fine structure of bovine morulae and blastocyst in vivo and in vitro. Anatomy and Embryology, v.199, n.16, p.516-527, 1999.

BONI, R.; TOSTI, E.; ROVIELLOS, S. et al. Intracellular communications in vivo and in vitro produced bovine embryo. Biology of Reproduction, v.61, p.1050-1055, 1999.

CAMARGO, L.S.A.; OLIVEIRA, R.S.; VIANA, J.H.M. et al. Comparison of two vitrification protocols for crossbred Bos indicus x Bos Taurus in vitro produced embryos. Reproduction, Fertility and Development, v.16, n.1-2, p.164, 2004.

$\mathrm{CHO}, \mathrm{K}$. Comparison of assisted hatching on cellular fragment portion and empty perivitelline space in poor embryos. Fertility and Sterility, v.78, p.S187, 2002 (suppl. 1).

COSTA, E.P.; NOGUEIRA, J.C.; CAMARGOS, E.R.S. et al. Cultivo "in vitro" de ovócitos bovinos em diferentes sistemas. II Aspectos ultra-estruturais. Arquivo Brasileiro de Medicina Veterinária e Zootecnia, v.9, n.5, p.561-574, 1997.

DIEZ, C.; NEYMAN, Y.; LEBOURHIS, D. et al. Delipidating in vitro produced bovine zygote: Effect on further development and consequences for freazability. Theriogenology, v.56, p.923-936, 2001.

DONNAY, I.; AUQUIER, P.; KAIDI, S. et al. Vitrification of in vitro produced bovine blastocysts: methodological studies and developmental capacity. Animal Reprodution Science, v.52, p. 93-104, 1998.

FOLHADELLA, I.M.; OLIVEIRA, R.S.; POLISSENI, J. et al. Vitrificação de embriões bovinos produzidos in vitro. In: REUNIÃO ANUAL DA SOCIEDADE BRASILEIRA DE ZooteCniA, 2004, 41., Campo Grande. Anais... Campo Grande: Sociedade Brasileira de Zootecnia, 2004. (CD-ROM).

GOMEZ, E.; DIEZ, C. Effects of glucose and protein sources on bovine embryo development in vitro. Animal Reprodution Science, v.58, p.23-37, 2000.

HASLER J.F.; HURTGEN P.J.; JIN Z.Q. et al. Survival of IVFderived bovine embryos frozen in glycerol or ethylene glycol. Theriogenology, v.48, p.563-579, 1997.

KAIDI, S.; van LANGENDONCKT, A.; MASSIP, A. et al. Cellular alteration after dilution of cryoprotective solutions used for the vitrification of in vitro produced bovine embryos. Theriogenology, v.52, n.3, p.515-525, 1999.

KHURANA, N.K.; NIEMANN, H. Effects of cryopreservation on glucose metabolism and survival of bovine morulae and blastocysts derived in vitro or in vivo. Theriogenology, v.54, p. 313-326, 2000.

LAZAR, L. The vitrification of in vitro fertilized cows blastocysts by open pulled straw method. Theriogenology, v.54, p.571578,2000

LAZAR, L.; ŠPAK, J.; DAVID, V. The vitrification of in vitro fertilized cow blastocysts by the open pulled straw method. Theriogenology, v.54, n.4, p.571-578, 2000.

LEIBO, S. P. Commercial production of pregnancies from oneste $^{\text {TM }}$ diluted frozen-thawed bovine embryos. Theriogenology, v. 25, n.1, p.166, 1986a.
LEIBO, S.P. Cryobiology: preservation of mammalian embryos. Basic Life Science, v.37, p.251-272, 1986b.

LEIBO, S.P.; WINNINGER D. Production of bovine pregnancies from embryos transported at $0^{\circ} \mathrm{C}$ by air. Theriogenology, v.25, n. 1, p. $165,1986$.

MARTÍNEZ, G.A.; VALCÁRCEL, A.; DE LAS HERAS, M.A. et al. Vitrification of in vitro produced bovine embryos: in vitro and in vivo evaluations. Animal Reproduction Science, v.73, p.11-21, 2002 .

MASSIP, A. Cryopreservation of embryo of farm animals. Domestic Animal, v.36, p.49-55, 2001.

MCEVOY, T.G. Manipulation of domestic animal embryos and implications for development. Reproduction Domestic Animal, v.38, n.4, p.268-275, 2003.

MEZZALIRA, A.; SANTOS, R.M.; BARRETA, M. et al. Transferência de embriões bovinos produzidos in vitro: efeito da vitrificação e do transporte. Acta Scientiae Veterinariae, v.32, p.164, 2004 (supl.).

NIEMANN, H.; WRENZYCKI; C. Alterations of expression of developmentally important genes in preimplantation bovine embryos by in vitro culture conditions: implications for subsequent development. Theriogenology, v.53, n.1, p.21-34, 2000.

PALMA, G.A. Biotecnologia de la reproducion. 1.ed. Balcarse: Ediciones Instituto Nacional de Tecnologia Agropecuaria, 2001. $693 \mathrm{p}$.

PARRISH J.J.; SUSKO-PARRISH J.L.; LEIBFRIED-RUTLEDGE M.L. et al. Bovine in vitro fertilization with frozen-thawed semen. Theriogenology, v.25, p.591-600, 1986.

PUGH, P.A.; TERVIT, H.R.; NIEMANN, H. Effects of vitrification medium composition on the survival of bovine in vitro produced embryos, following in straw-dilution, in vitro and in vivo following transfer. Animal Reproduction Science, v.58, p.9-22, 2000.

RIZOS, D.; GUTIERREZ-ADAN, A.; PEREZ-GARNELO, S. et al. Bovine embryo culture in the presence or absence of serum: implications for blastocyst development, cryotolerance, and messenger RNA expression. Biology of Reproduction, v.68, p. 236-243, 2003.

RIZOS, D.; WARD, F.; BOLAND, M.P. et al. Effect of culture on the yield and quality of bovine blastocysts as assessed by survival after vitrification. Theriogenology, v.56, p.1-16, 2001.

SHAMSUDDIN, M.; NASAR, A.; GUPTA, T.K.S.P. Thermodynamic investigations of liquid Te-saturated $\mathrm{PbSe}-\mathrm{PbTe}$ solid solutions. Thermochimica Acta, v.232, n.2, p.303-315, 1994.

SOCIEDADE INTERNACIONAL DE TRANSFERÊNCIA DE EMBRIÕES - IETS. Manual da Sociedade Internacional de Transferência de Embriões. 3.ed. Illinois: IETS, 1998. 180p.

SOMMERFELD, V.; NIEMANN, H. Cryopreservation of bovine in vitro produced embryos using ethylene glycol in controlled freezing or vitrification. Cryobiology, v.38, p.95-105, 1999.

TAKAHASHI, H.; KUWAYAMA, M.; HAMANO, S. et al. Effect of b-mercaptoethanol on the viability of IVM/IVF/IVC bovine embryos during long-distance transportation in plastic straws. Theriogenology, v.46, n.6, p.1009-1015, 1996.

VAJTA, G.; HOLM, P.; GREVE, T. et al. Factors affecting survival rates of in vitro produced bovine embryos after vitrification and direct in straw rehydration. Animal Reproduction Science, v.45, p.191-200, 1996.

YANG, N.S.; DUFF, R.; LU, K.H. et al. Effect of storage temperature and time on the viability of bovine embryos produced in vitro. Theriogenology, v.35, n.1, p.297, 1991.

YOUNG, L.E.; BUTTERWITH, S.C.; WILMUT, I. Novel method for quantifying mRNA levels in single embryos. Theriogenology, v.49, n.1, p.192, 1998.

Recebido: $24 / 11 / 05$ Aprovado: 01/07/06 